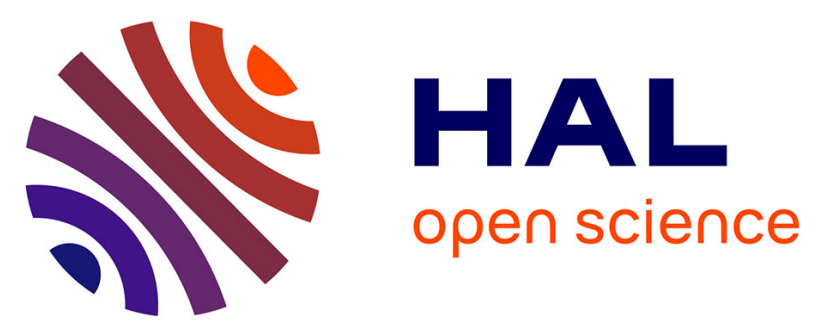

\title{
Interictal psychiatric comorbidities of drug-resistant focal epilepsy: Prevalence and influence of the localization of the epilepsy
}

Claire Jansen, Léa Francomme, Jean-Pierre Vignal, Caroline Jacquot, Raymund Schwan, Louise Tyvaert, Louis Maillard, Coraline Hingray

\section{To cite this version:}

Claire Jansen, Léa Francomme, Jean-Pierre Vignal, Caroline Jacquot, Raymund Schwan, et al.. Interictal psychiatric comorbidities of drug-resistant focal epilepsy: Prevalence and influence of the localization of the epilepsy. Epilepsy \& Behavior, 2019, 94, pp.288-296. 10.1016/j.yebeh.2018.06.046 . hal-01947262

\section{HAL Id: hal-01947262 \\ https://hal.science/hal-01947262}

Submitted on 22 Oct 2021

HAL is a multi-disciplinary open access archive for the deposit and dissemination of scientific research documents, whether they are published or not. The documents may come from teaching and research institutions in France or abroad, or from public or private research centers.
L'archive ouverte pluridisciplinaire $\mathbf{H A L}$, est destinée au dépôt et à la diffusion de documents scientifiques de niveau recherche, publiés ou non, émanant des établissements d'enseignement et de recherche français ou étrangers, des laboratoires publics ou privés.

\section{(ㄷ)(1) $\$$}

Distributed under a Creative Commons Attribution - NonCommerciall 4.0 International 


\section{Inter-ictal psychiatric comorbidities of drug-resistant focal epilepsy: prevalence and influence of the epilepsy localization}

Claire Jansen, Léa Francomme, Jean Pierre Vignal, Caroline Jacquot, Raymund Schwan, Louise Tyvaert, Louis Maillard, Coraline Hingray

\section{ABSTRACT}

Psychiatric comorbidities are 2 to 3 time more frequent in epilepsy, than in the general population. This study aimed to prospectively assess: (i)the prevalence of specific and nonspecific inter-ictal psychiatric comorbidities in a population of patients with drug-resistant focal epilepsy, (ii) the influence of epilepsy lateralization and localization on these psychiatric co-morbidities .

In this prospective monocentric study, we collected demographic data, characteristics of the epilepsy, inter-ictal psychiatric comorbidities, mood, anxiety and alexithymia dimensions. We used criteria from DSM IV (Mini International Mental Interview), diagnosis criteria for specific comorbidites and validated mood and anxiety scales (general and specific for epilepsy).

Among 87 enrolled patients (39 male, 48 female), 52.9\% had at least one psychiatric comorbidity. The most common comorbidity was anxiety disorder: $28.7 \%$ according to the MINI and 38.4\% according to the GAD 7 (Generalized Anxiety Disorder 7)). Mood disorders were the second most frequent psychiatric comorbidity: $21.8 \%$ of our patients had interictal dysphoric disorders and $16.1 \%$ presented major depressive disorders according to the MINI, and $17.2 \%$ according to the NDDIE (Neurological Disorders Depression Inventory for Epilepsy).

Patients with temporal epilepsy had a higher prevalence of psychiatric comorbidities than patients with extra-temporal epilepsy $(\mathrm{p}=0.002)$, probably related to a higher rate of anxiety disorders in this subgroup $(\mathrm{p}=0.012)$. Prevalence of psychiatric disorders pre-existing to epilepsy in patients was higher in right than in left-sided epilepsy $(\mathrm{p}=0.042)$. No difference was found according to limbic involvement at seizure onset.

Overall, this article highlighted a very high proportion of anxiety disorders in these patients with focal drug-resistant epilepsy and the necessity to systematically detect them and thus lead to a specific treatment; 


\section{INTRODUCTION}

Lifetime prevalence of psychiatric disorders has been reported in 30 to $80 \%$ of patients with drug-resistant focal epilepsy. Many recent epidemiological studies have shown that the prevalence of depression, anxiety and psychotic disorders was higher in epileptic patients than in general population (Kwon and Park, 2014). Several studies have focused on limited aspects of these various comorbidities, overlooking specific co-morbidities such as interictal mood disorders, isolated feelings of persecution, anticipatory anxiety of seizures, or even additional non-specific comorbidites such as eating behavior disorder (Jones et al., 2005). Non-specific psychiatric disorders can affect everyone whereas specific disorders affect only patients with epilepsy. In addition, many studies have used diagnostic criteria from the international classifications of psychiatric diseases ICD 10 (Regier et al., 1994) and DSM IV while numerous disabling psychiatric symptoms reported by patients are often atypical and specific to epilepsy and do not meet the usual criteria of standard classifications (Toffol, 2003). Epilepsy-specific clinical criteria have been recently proposed (Mula et al., 2008) and validated for rapid detection of depression, (e.gNDDIE -Neurological Disorders Depression Inventory for Epilepsy), and of anxiety disorder (e.g GAD 7 -Generalized Anxiety Disorder 7). Moreover, psychiatric disorders specific to epilepsy such as interictal dysphoric disorder have been recently emphasized by the ILAE classification of neuropsychiatric disorders of epilepsy ILAE (Krishnamoorthy et al., 2007) according to Blumer's criteria.

These psychiatric co-morbidities specifically associated to epilepsy are highly underdiagnosed and thus obviously inadequately treated. They may worsen the course of epilepsy itself, the social exclusion related to the seizures and the quality of life (Tedrus et al., 2013). Moreover, in active epilepsies, the presence of a depressive syndrome is a stronger predictor of impaired quality of life than the frequency of epileptic seizures, (Micoulaud-Franchi et al., 2017).

The purpose of this study was to describe the demographic data, the characteristics of epilepsy, and the prevalence of non-specific and epilepsy-specific psychiatric comorbidities in a population of patients with focal structural drug-resistant epilepsy in the clinical setting of pre-surgical evaluation.

The secondary objectives were to compare the prevalence and the nature of psychiatric disorders in patients with focal drug-resistant epilepsy in terms of epilepsy lateralization and localization (temporal vs. extra-temporal, limbic vs. extra-limbic). 
The methodology of this current prospective study was unique because of the extensive and comprehensive psychiatric evaluations performed by experienced psychiatrists in a tertiary center for epilepsy.

Our working hypothesis were that : (i) the prevalence of psychiatric co-morbidity was different according to the used diagnostic tool (specific vs. non specific international criteria) (Amiri and Hansen, 2015); (ii) psychiatric comorbidities were more common in patients with temporal lobe epilepsy and in those with limbic epilepsy, (iii) and the prevalence of psychiatric co-morbidity was different according to the lateralization of epilepsy.

\section{$\underline{\text { METHODS }}$}

This epidemiological, observational, and prospective monocentric study collected data from the systematic psychiatric evaluation of patients with drug-resistant focal epilepsy, hospitalized from February 2016 to May 2017 in the epileptology department of Nancy University Hospital for pre-surgical work-up.

Inclusion criteria

All consecutive patients undergoing a pre-surgical work-up in the epileptology unit of the Nancy University hospital between February 2016 and May 2017 and meeting the following inclusion criteria were proposed to participate:

_ Confirmed drug-refractory focal epilepsy diagnosis with, video-EEG recorded seizures, MRI and FDG-PET (according to the criteria of the ILAE (International League Against Epilepsy) (Kwan et al., 2010)

_age 18 or older

_French as their native langage

_ability to give their consent for the study.

All patients had focal or multifocal structural medically intractable epilepsy and were evaluated indeed in the setting of an Epilepsy Monitoring Unit. However, not all patients proceeded to epilepsy surgery. 
Clinical evaluation and data collection

The methodology was designed to comprehensively evaluate non-specific psychiatric disorders and psychiatric disorders specific to epilepsy, with hetero-evaluation and selfassessment tools. This methodology is part of our clinical evaluation protocol, including systematic psychiatric assessment of hospitalized patients with drug-resistant focal epilepsy. In this study, the data were collected prospectively.

Sociodemographic data including way of life, education and activity were collected.

Seizure data

Seizure related variables including seizure frequency and duration, medical history of head injury, febrile seizures, febrile encephalopathy were recorded and documented by epileptologists. Signs of clinical severity of seizures were sought: cranial trauma, loss of consciousness, tongue-biting or loss of urine during seizures.

Lateralization and localization of seizure foci was based on the recorded seizures during longterm video-EEG monitoring and imagery in all patients and additional video-SEEG (stereoelectroencephalography) in 54 out of 87 . Seizures were classified as: temporal/extra-temporal, right/left/bilateral and limbic/extra-limbic based on anatomo-electro-clinical correlations. Limbic seizures were defined as seizures with a clear medial temporal onset, either proven on SEEG recordings or on converging findings from phase 1 pre-surgical work-up : history of childhood febril seizures, hippocampal sclerosis, exceptionnal secondary generalization, typical medial temporal lobe seizure semiology involving viscero-sensitive symptoms, dreamy-state or déjà-vu, warning, delayed loss of contact, delayed oro-alimentary and gestural automatisms, duration of seizures > 1 minute (Maillard et al 2004).

We also collected ongoing anti-epileptic treatment and reported those who had treatment with a potentially negative psychotropic effect: Levetiracetam, vigabratin, perampanel, stiripentol, tiagabine, ethosuximide, felbamate, zonisamide, phénobarbital, phenytoine and topiramate.

Psychiatric data

Psychiatric disorders were evaluated by 2 psychiatrists experienced in specific epileptic disorders in three dimensions: 
-Non-specific psychiatric disorders evaluated by non specific tool

-Non-specific psychiatric disorders evaluated by tool specially validated in population with epilepsy

-Specific epilepsy psychiatric disorders

The chronology of early psychiatric disorders related to the onset of epileptic illness was sought.

- $\quad$ NON-SPECIFIC PSYCHIATRIC DISORDERS EVALUATED BY NON SPECIFIC TOOL:

Patients were assessed with a structured clinical interview based on Mini International Neuropsychiatric Interview (MINI) (Sheehan et al., 1998) completed with symptom-rating scales that has been validated for use in clinical as well as in research. For anxiety: STAI A (State trait anxiety scale: state)and STAI B: (State trait anxiety scale: traits) were performed. The STAI A is particularly used to control the level of anxiety at the moment of evaluation, and is not a diagnostic instrument. For mood evaluation, depression: heteroscale Beck 21.

Addiction, habit and eating disorder are explored in detail by MINI DSMIV, we add also the search for binge eating disorder according criteria from DSM 5.

The presence or absence of diagnosed family psychopathology, past history of psychiatric illness was also recorded.

- NON-SPECIFIC PSYCHIATRIC DISORDERS EVALUATED BY TOOL SPECIALLY VALIDATED IN POPULATION WITH EPILEPSY:

Patients passed specifics scales: NDDIE : (Neurological Disorders Depression Inventory for Epilepsy) (Micoulaud-Franchi et al., 2015) . The NDDI-E was developed to evaluate the Major Depressive Disorder (as defined in the DSM-IV) but taking into account the confounding variables in patient with epilepsy: in particular anti-epileptic drug effect, and cognitive deficit.

The GAD 7 (generalized anxiety disorder). (Micoulaud-Franchi et al., 2016) was used. The GAD-7 evaluate the Generalized anxiety disorder of the DSM-IV and has been validated in patient with epilepsy.

NDDIE et GAD 7 have been validated as highly sensitive and specific screening tools

- SPECIFIC INTER-ICTAL PSYCHIATRIC COMORBIDITIES (NO DIRECT CHRONOLOGICAL RELATION WITH THE SEIZURE): 
These comorbidities were systematically inverstigated. (Krishnamoorthy et al., 2007): inter ictal dysphoria (Blumer syndrome), anticipatory anxiety, situations avoided and intensity of a non-specific persecution experience has been measured.

Interictal dysphoric disorder (according to Blumer's criteria) can be defined as follows: at least three episodes of a few hours to a few days, grouping together at least three criteria among the following eight: depressed mood, asthenia, atypical pain, insomnia, fear and anxiety, irritability, euphoric mood and instability of mood.

Anticipatory anxiety was defined as the agonizing fear of seizure . Situations avoided were defined as an activity avoided (social, sports or daily activity) by the patient beacause of the fear of a seizure. Non-specific persecution experience was a feeling of persecution criticized by the patient, and isolated, ie without other psychotic elements (disorganization, hallucinations, other delusions, mental automatism).

We finally assessed iatrogenic's mental health and behavioral disturbances with antiepileptic drug.

Statistical analyses

We compared demographic data, seizure data and psychiatric data according to the lateralization and localization of seizure focus (left vs right; temporal vs extra temporal) and according to limbic involvement (limbic vs extra limbic).

Binary variables were analyzed by Khi 2 test and quantitative variables were analyzed by Student test with Statistica 10. P value of less than 0.05 was considered statistically significant.

\section{RESULTS}

\section{OVERALL DESCRIPTION OF THE POPULATION STUDIED}

\section{1- 1- DEMOGRAPHIC DATA}

Of the 87 patients in the cohort, $39(44.8 \%)$ were men. Sex ratio was 0.8 .

The mean age at inclusion was 34.3 years (range 18-62; standard deviation 11.9). 
$55.2 \%$ lived with a partner; $24.1 \%$ patients lived alone and $20.7 \%$ lived with their parents or in institutions. $41.4 \%$ had one or more children. $35.6 \%$ drove a car regularly. $58.6 \%$ had a professional activity or are students whether $41.4 \%$ of them do not work. Only $12.6 \%$ patients $(12.6 \%)$ were on sick leave at the time of inclusion. $31 \%$ of patients in the cohort received state financial assistance .

\section{1-2- CHARACTERISTICS OF EPILEPSY}

The average duration of evolution of epilepsy was 18.5 years (standard deviation 15.8). For $43.7 \%$ patients, cerebral MRI revealed an epileptogenic lesion. $97.7 \%$ of our patients were taking AE drug, and $88.5 \%$ had at least one anti-epileptic molecule with a known negative psychotropic effect. The included patients take an average of 2.2 anti-epileptic drugs.

$46 \%$ of our study population had a right epilepsy, $43.7 \%$ left, and $10.3 \%$ patients had a bilateral or an unknown lateralization. $72.4 \%$ had temporal epilepsy, versus $26.5 \%$ extra temporal. $1.1 \%$ of our patients had multifocal epilepsy and did not fall into the temporal or extra-temporal category. Finally $48.3 \%$ had limbic epilepsy. 
Table 1 : Characteristics of epilepsy

\begin{tabular}{|l|l|}
\hline Evolution time of epilepsy (average (standard deviation)) & $18.5(15.8)$ \\
\hline Secondarily generalized seizures \% (N) & $39 \%(34)$ \\
\hline MRI lesions \% (N) & $43.7 \%(38)$ \\
\hline Anti-epileptic drugs \% (N) & $97.7 \%(85)$ \\
\hline At least one antiepileptic with potential negative psychotropic effect \% (N) & $88.5 \%(77)$ \\
\hline Right epilepsy \% (N) & $46.0 \%(40)$ \\
\hline Left epilepsy \% (N) & $43.7 \%(38)$ \\
\hline Bilateral or non lateralized epileptogenic focus \% (N) & $10.3 \%(9)$ \\
\hline Temporal epilepsy \% (N) & $72.4 \%(63)$ \\
\hline Extra temporal epilepsy \% (N) & $26.5 \%(23)$ \\
\hline Limbic epilepsy \% (N) & $48.3 \%(42)$ \\
\hline Extra limbic (\%) (N) & $51.7 \%(45)$ \\
\hline
\end{tabular}

\section{1-3- INTER-ICTAL PSYCHIATRIC DISORDERS}

Data are summarize in table 2.

$55.2 \%$ had an on-going or previous psychiatric follow-up,16.1\% had already been hospitalized in psychiatric department and $14.9 \%$ had attempted suicide at least once.

$60.9 \%$ of our patients had at least one psychiatric history and 52.9\% had a on-going psychiatric disorder at the time of inclusion.

$42.5 \%$ had a history of psycho-traumatism. 
The psychiatric disorder pre-existed the onset of epilepsy in $31 \%$ of our patients and for $58.6 \%$ a psychiatric disorder appeared after the beginning of the epilepsy.

\section{MOOD DISORDERS}

\section{MOOD DISORDERS EVALUATED BY NON SPECIFIC TOOLS:}

The MINI revealed that mood disorders (44.8\%) represented the most frequent psychiatric history in our cohort but was on-going in only $16.1 \%$ of our patients at the time of evaluation. The results of the Beck 21 confirmed this result: $14.9 \%$ had a positive result on this selfquestionnaire.

$17.2 \%$ of patients received antidepressant treatment at the time of evaluation.

\section{MOOD DISORDERS SCREENED BY SPECIFIC TOOL:}

$17.2 \%$ of our patients had a positive NDDIE

\section{SPECIFIC MOOD DISORDERS :}

At the time of evaluation, an on-going inter -ictal dysphoric disorder was present in $21.8 \%$ of our population.

DRUG-INDUCED MOOD DISORDERS:

$17.2 \%$ cohort had a previous or on-going a drug-induced mood disorder.

\section{ANXIETY DISORDERS}

\section{ANXIETY DISORDERS EVALUATED BY NON SPECIFIC TOOLS:}

The MINI revealed that anxiety disorders represented the most frequent psychiatric comorbidity at evaluation: $28.7 \%$; this was confirmed by the results of STAI A (anxiety state) positive for $10.8 \%$ of patients, and STAI B (anxiety traits) positive in $18.9 \%$ of patients.

At that time only $10.3 \%$ of patients received anti-anxiety medication.

ANXIETY DISORDERS SCREENED BY TOOL VALIDATED IN POPULATION WITH EPILEPSY:

$38.4 \%$ of our patients had a positive result in GAD 7.

SPECIFIC ANXIETY DISORDERS :

$52.9 \%$ of patients had an anticipatory anxiety.

There was at least one situation avoidance for $39.1 \%$ of patients.

DRUG-INDUCED ANXIETY DISORDERS:

There was a drug-induced anxiety disorder in $2.3 \%$ of patients.

\section{PSYCHOTIC DISORDERS}




\section{PSYCHOTIC DISORDERS EVALUATED BY NON SPECIFIC TOOL:}

The MINI found an ongoing psychotic disorder for $8 \%$ of our patients, as well as a history of psychotic disorder for $5.7 \%$ of patiens. $4.6 \%$ of patients were treated with an anti psychotic at the time of inclusion.

\section{SPECIFIC PSYCHOTIC DISORDERS:}

$11.5 \%$ of patients in the cohort had a isolated feeling of persecution. In these patients, the average intensity of this feeling of persecution was 7(1.6)/10.

\section{DRUG-INDUCED PSYCHOTIC DISORDERS}

The drug-induced psychotic disorder concerned $4.6 \%$ of patients in the cohort.

\section{ADDICTIONS AND EATING DISORDERS}

$28.7 \%$ had at least one addiction found at the MINI at the time of the evaluation. The eating disorders at inclusion was present in $1.1 \%$ of the study population.

Table 2 : Inter-ictal psychiatric disorders in drug-resistant focal epilepsy

\begin{tabular}{|c|c|c|c|c|}
\hline \multirow{2}{*}{$\begin{array}{l}\text { Classification of } \\
\text { inter-ictal } \\
\text { psychiatric } \\
\text { disorders }\end{array}$} & \multirow[t]{2}{*}{ Sub categories } & \multicolumn{3}{|c|}{ Type } \\
\hline & & $\begin{array}{c}\text { Mood disorders } \\
\%(\mathrm{~N})\end{array}$ & $\begin{array}{c}\text { Anxiety disorders } \\
\%(\mathrm{~N})\end{array}$ & $\begin{array}{c}\text { Psychotic disorders } \\
\%(\mathrm{~N})\end{array}$ \\
\hline $\begin{array}{l}\text { Non Specific } \\
\text { Disorder }\end{array}$ & $\begin{array}{l}\text { According to } \\
\text { DSM IV criteria } \\
\text { with MINI* } \\
\text { And non } \\
\text { specific scales } \\
\text { (Beck 21, STAI } \\
\text { A and B) }\end{array}$ & $\begin{array}{l}\text { Major Depressive } \\
\text { Disorder : } 12.6 \% \\
\text { (11) } \\
\\
\text { Depression } \\
\text { according a } \\
\text { positive score at } \\
\text { scale Beck } 21: \\
14.9 \%(13)\end{array}$ & $\begin{array}{l}\text { Generalized Anxiety } \\
\text { Disorder : } 10.3 \% \text { (9) } \\
\text { Obsessive-Compulsive } \\
\text { Disorder : } 2.3 \%(2) \\
\\
\text { Panic Disorder Without } \\
\text { Agoraphobia : } 12.6 \% \text { (11) } \\
\text { Agoraphobia Without } \\
\text { History of Panic } \\
\text { Disorder : } 6.9 \%(6) \\
\text { Social Phobia : } 1.1 \% \text { (1) } \\
\text { Posttraumatic Stress } \\
\text { Disorder : } 3.4 \% \text { (3) } \\
\text { Anxiety state evaluated by } \\
\text { positive score at STAI } \\
\text { A**: } 10.8 \% \text { (9) }\end{array}$ & $\begin{array}{l}\text { Psychotic Disorders: } \\
8 \% \text { (7) }\end{array}$ \\
\hline
\end{tabular}




\begin{tabular}{|c|c|c|c|c|}
\hline & & & $\begin{array}{l}\text { Anxiety trait evaluated by } \\
\text { positive score at STAI } \\
B^{* *}: 18.9 \%(16)\end{array}$ & \\
\hline & $\begin{array}{l}\text { According to } \\
\text { specific tool or } \\
\text { tool validated in } \\
\text { epilepsy }\end{array}$ & $\begin{array}{l}\text { Depression } \\
\text { according a } \\
\text { Positive score at } \\
\text { scale } \\
\text { NDDIE***: } 17.2 \\
\%(15)\end{array}$ & $\begin{array}{l}\text { General anxiety according } \\
\text { a Positive score at scale } \\
\text { GAD 7****: } 38.4 \% \text { (33) }\end{array}$ & \\
\hline Specific Disorder & & $\begin{array}{l}\text { Interictal } \\
\text { dysphoric disorder } \\
21.8 \%(19)\end{array}$ & $\begin{array}{l}\text { Anticipatory anxiety: } \\
52.9 \%(46) \\
\text { At least one avoidance for } \\
\text { fear of a seizure: } 39.1 \% \\
(34)\end{array}$ & $\begin{array}{l}\text { Isolated feeling of } \\
\text { persecution: } 11.5 \% \\
\text { (10) }\end{array}$ \\
\hline Iatrogenic & $\begin{array}{l}\text { Anti epileptic } \\
\text { drugs Induced }\end{array}$ & $\begin{array}{l}\text { AED-Induced } \\
\text { Mood } \\
\text { Disorder : } 17.2 \% \\
(15)\end{array}$ & $\begin{array}{l}\text { AED induced Anxiety } \\
\text { symptoms or nervousness } \\
\text { or symptoms of increased } \\
\text { arousal }: 2.3 \% \text { (2) }\end{array}$ & $\begin{array}{l}\text { AED induced } \\
\text { Psychotic Disorder: } \\
4.6 \%(4)\end{array}$ \\
\hline
\end{tabular}

* MINI ( Mini International Neuropsychiatric Interview) ; ** STAI (State trait anxiety scale) ; *** NDDIE (Neurological Disorders Depression Inventory for Epilepsy) ; ****GAD 7 (Generalized anxiety disorder) ;; $\mathrm{N}=$ number of patient

\section{2- INTERACTIONS BETWEEN EPILEPSY LATERALIZATION AND INTERICTAL PSYCHIATRIC CO-MORBIDITIES}

9 patients had bilateral or unknown epilepsy lateralization and were not included in the statistical analyzes comparing the effect of right or left epilepsy lateralization.

40 patients had a right lateralized epilepsy, and 38 a left lateralized epilepsy .

The left and right epilepsy groups did not significantly differ in terms of age of epilepsy onset (respectively $17.6(13.2)$ vs $16(10.3) \mathrm{p}=0.552$ ), mean duration of epilepsy (respectively 15.8 (12.7) vs 18 ( 12.9$) ; p=0.467$ ), neurological history (history of trauma cranial, for example, $15 \%$ vs $13.2 \% ; \mathrm{p}=0.815)$, and signs of clinical severity of seizures. 
Data are summarized in table 3.

\section{PSYCHIATRIC HISTORY}

With respect to psychiatric data, the left and right epilepsy groups did not differ in terms of previous psychiatric follow-up (respectively $52.5 \%$ vs $60.5 \% ; \mathrm{p}=0.475$ ), previous hospitalization in psychiatry department (respectively $10 \%$ vs $23.7 \% ; \mathrm{p}=0.105$ ), presence of at least one on-going psychiatric disorder at the MINI ( respectively $52.5 \%$ vs $52.6 \%$; $=$ 0.991), psychiatric history at the MINI ( respectively $57.5 \%$ vs $68.4 \% ; \mathrm{p}=0.318$ ), psychiatric family history ( respectively $32.5 \%$ vs $36.8 \%$; $=0.921$ ), and of personal history of suicide attempt ( respectively $15 \%$ vs $13.2 \% ; \mathrm{p}=0.577$ ).

However, patients with right epilepsy had a significantly more frequent psychiatric disorder history pre-existing to epilepsy onset (respectively $42.5 \%$ vs $21.1 \% ; \mathrm{p}=0.042$ ). There was no significant difference between these two groups, for psychiatric disorders that appeared after the onset of epilepsy (respectively $52.5 \%$ vs $71.1 \%$; $=0.092$ ).

Table 3: Comparison of the prevalence of mood disorders according to lateralization of epilepsy

\begin{tabular}{|l|c|c|c|}
\hline & $\begin{array}{c}\text { EPILEPSY } \\
\text { ON THE } \\
\text { RIGHT N=40 } \\
\%(\mathrm{~N})\end{array}$ & $\begin{array}{c}\text { EPILEPTOGE } \\
\text { NIC FOCUS } \\
\text { ON THE } \\
\text { LEFT N=38 } \\
\%(\mathrm{~N})\end{array}$ & $\mathrm{p}$ \\
\hline Major depressive disorder & $5 \%(2)$ & $18.4 \%(7)$ & 0.064 \\
\hline $\begin{array}{l}\text { Existence of at least one mood } \\
\text { disorder at the MINI* }\end{array}$ & $35 \%(14)$ & $55.3 \%(21)$ & 0.072 \\
\hline Inter ictal dysphoric disorder & $22.5 \%(9)$ & $18.4 \%(7)$ & 0.656 \\
\hline $\begin{array}{l}\text { Depression according a positive } \\
\text { score at scale Beck 21 }\end{array}$ & $17.7 \%(7)$ & $18.8 \%(7)$ & 0.908 \\
\hline $\begin{array}{l}\text { Depression screnned by positive } \\
\text { score at scale NDDIE ** }\end{array}$ & $20.6 \%(8)$ & $24.1 \%(9)$ & 0.735 \\
\hline Bipolar disorder & 0 & 0 & 0.176 \\
\hline Drug induced mood disorder & $10 \%(4)$ & $21.1 \%(8)$ & \\
\hline
\end{tabular}

*MINI ( Mini International Neuropsychiatric Interview) ; **NDDIE (Neurological Disorders Depression Inventory for Epilepsy); *** GAD 7 (Generalized anxiety disorder) ; $\mathrm{N}=$ number of patient 


\section{MOOD DISORDERS}

\section{MOOD DISORDERS EVALUATED BY NON SPECIFIC TOOLS}

The left and right epilepsy groups did not differ in terms of mood disorders defined as the existence of at least one current mood disorder at the MINI (respectively $7.5 \%$ vs $18.4 \%$; $\mathrm{p}=$ 0.149 ) or at least one history of mood disorder at the MINI ( respectively $35 \%$ vs $55.3 \%$; $=0.072)$ or Beck 21 positive ( respectively $17.7 \%$ vs $18.8 \% ; \mathrm{p}=0.908)$.

They did did not differ in term of antidepressant therapy at the time of evaluation (respectively $12.5 \%$ vs $21.1 \%$; $\mathrm{p}=0.311$ ).

Major depressive disorder tended to be more frequent in patients with left epilepsy compared to patients with right epilepsy (respectively $5 \%$ vs $18.4 \%$; $=0.064$ ).

MOOD DISORDERS SCREENED BY SPECIFIC TOOL

The left and the right groups did not differ for the NDDIE results (respectively $20.6 \%$ vs 24.1 $\% ; \mathrm{p}=0.735)$

\section{SPECIFIC MOOD DISORDERS}

The left and the right groups did not differ in terms of interictal dysphoric disorder (respectively $22.5 \%$ vs $18.4 \% ; \mathrm{p}=0.656$ ).

\section{DRUG INDUCED MOOD DISORDERS}

The left and the right groups did not differ in terms of drug-induced mood disorders (respectively $10 \%$ vs $21.1 \% ; \mathrm{p}=0.176$ ).

\section{ANXIETY DISORDERS}

\section{ANXIETY DISORDERS EVALUATED BY NON SPECIFIC TOOLS}

The left and the right epileptic patients did not differ in terms of the presence of at least one current anxiety disorder at the MINI ( respectively $32.5 \%$ vs $28.9 \% ; \mathrm{p}=0.734$ ), at least one history of anxiety disorder at the MINI ( respectively $32.5 \%$ vs $18.4 \% ; \mathrm{p}=0.155$ ), as well as in terms of the results of STAI A ( respectively $8.8 \%$ vs $12.5 \% ; \mathrm{p}=0.628$ ) and STAI B ( respectively $20.6 \%$ vs $15.6 \% ; \mathrm{p}=0.601)$. The groups did not differ neither in terms of ongoing anxiolytic treatment at inclusion (respectively 7.5 vs $10.5 ; \mathrm{p}=0.640$ ).

\section{ANXIETY DISORDERS SCREENED BY TOOL VALIDATED IN POPULATION WITH EPILEPSY}

The left and the right groups did not differ in terms of depression according positive score at scale GAD 7 (respectively $37.2 \%$ vs $40 \% ; \mathrm{p}=0.903$ ) 


\section{SPECIFIC ANXIETY DISORDERS}

There is no difference in terms of anticipatory anxiety, ( respectively $47.5 \%$ vs $44.7 \%$; $\mathrm{p}=0.807$ ) neither for avoidance resulting from anxiety ( respectively $45 \%$ vs $47,4 \% ; \mathrm{p}=0,834$ ).

\section{DRUG-INDUCED ANXIETY DISORDERS}

Similarly, the two groups did not differ according to the existence of drug-induced anxiety disorder (respectively $0 \%$ vs $2.6 \% ; \mathrm{p}=0.302$ ).

\section{PSYCHOTIC DISORDERS}

\section{PSYCHOTIC DISORDERS EVALUATED BY NON SPECIFIC TOOL}

The left and right groups did not differ in terms of psychotic histories at the MINI (respectively $5 \%$ vs $7.9 \% ; p=0.602$ ) and current psychotic symptoms such as the presence of hallucinations (respectively $0 \%$ vs $2.6 \%$; $=0.302$ ) or psychic disorganization.

The two groups did not differ in terms of on-going anti-psychotic treatment (respectively $5 \%$ vs $5.3 \% \mathrm{p}=0.958)$.

\section{SPECIFIC PSYCHOTIC DISORDERS}

The two groups did not differ in terms of the presence of an isolated feeling of persecution (respectively $12.5 \%$ vs $7.9 \%$; $=0.503$ ).

However, the intensity of this feeling quantified on an imaginary scale graduated from 0 to 10 ( 0 being the absence of persecution feeling and the most intense persecution feeling possible) is significantly higher in patients with left-sided epilepsy $(\mathrm{p}=0.012)$. Indeed, the intensity of the persecution experience was, on average, $7.8(0.8) / 10$ for patients with left-sided epilepsy compared to $5.8(1.1) / 10$ for patients with right-sided epilepsy $(\mathrm{p}=0.012)$.

\section{DRUG-INDUCED PSYCHOTIC DISORDERS}

The two groups did not differ in terms of drug-induced psychoses (respectively $2.5 \%$ vs 7.9 $\% ; \mathrm{p}=0.280)$.

\section{ADDICTIONS AND EATING DISORDERS}

The left and the right groups did not differ in terms of addictive or dietary behaviors. 
3- INTERACTION BETWEEN EPILEPSY LOCALIZATION (TEMPORAL VS; EXTRATEMPORAL) AND INTERICTAL PSYCHIATRIC CO-MORBIDITIES.

63 patients had temporal epilepsy and 23 had extra temporal epilepsy. 1 patient with multifocal epilepsy was excluded from statistics concerning this lobar location of epilepsy.

Patients with extra-temporal epilepsy were significantly younger than patients with temporal epilepsy (respectively 27.7 vs 36.5 years; $\mathrm{p}=0.002$ ). The temporal and the extra temporal groups did not differ in terms of disease duration (respectively 20.3 (SD :16.8) vs 13.7 (SD : 12.6) $; \mathrm{p}=0.089$ ), perinatal neurological history (respectively $7.9 \%$ vs $0 \% ; p=0.164$ ), or the presence of a MRI visible epileptogenic lesion ( respectively $38.1 \%$ vs $60.1 \%$; p = $0.169)$.

Nevertheless, patients with extra-temporal epilepsy took significantly more antiepileptic drugs than patients with temporal epilepsy (respectively 2.1 (SD: 0.9) vs. $2.6(\mathrm{SD}: 0.8) \mathrm{p}=0.012$ ).

\section{PSYCHIATRIC HISTORY}

A history of psychiatric follow-up was more frequent in patients with temporal than extratemporal epilepsy (respectively $63.5 \%$ vs. 30.4; $\mathrm{p}=0.006$ ). The existence of at least one psychiatric disorder after the onset of epilepsy was significantly higher in the temporal epilepsy group than in the extra temporal epilepsy group (respectively $69.8 \%$ vs $34.8 \%$, p = 0,002 ) as well as the existence of at least one psychiatric history at the MINI ( respectively $69.8 \%$ vs $30.4 \% \mathrm{p}=0.003)$, of an ongoing psychotropic treatments at inclusion ( respectively $25.4 \%$ vs $4.3 \%$; $=0.014)$, and number of ongoing psychotropic treatments ( respectively $0.37(0.7)$ vs $0.04(0.2) ; \mathrm{p}=0.040)$.

Table 4: Comparison of inter-ictal psychatric disorders according to localization of epilepsy.

\begin{tabular}{|c|l|c|c|c|}
\hline & & $\begin{array}{c}\text { TEMPORAL } \\
\mathrm{N}=63 \\
\%(\mathrm{~N})\end{array}$ & $\begin{array}{c}\text { EXTRA } \\
\text { TEMPORAL } \\
\mathrm{N}=23 \\
\%(\mathrm{~N})\end{array}$ & $\mathrm{p}$ \\
\hline $\begin{array}{c}\text { Mood } \\
\text { disorders }\end{array}$ & $\begin{array}{l}\text { Existence of at least one } \\
\text { current mood disorder at the } \\
\text { MINI }\end{array}$ & $15.9 \%(10)$ & $13 \%(3)$ & 0.746 \\
\hline $\begin{array}{c}\text { Anxiety } \\
\text { disorders }\end{array}$ & $\begin{array}{l}\text { Existence of at least one } \\
\text { current anxiety disorder at } \\
\text { the MINI }\end{array}$ & $36.5 \%(23)$ & $8.7 \%(2)$ & $\mathbf{0 . 0 1 2}$ \\
\hline
\end{tabular}




\begin{tabular}{|c|l|c|c|c|}
\hline & $\begin{array}{l}\text { Existence of at least one } \\
\text { history of anxiety disorder in } \\
\text { the MINI * }\end{array}$ & $30.2 \%(19)$ & $8.7 \%(2)$ & $\mathbf{0 . 0 4 0}$ \\
\cline { 2 - 4 } & $\begin{array}{l}\text { Anxiety state evaluated by } \\
\text { positive score at STAI A* }\end{array}$ & $11.3 \%(7)$ & $5 \%(1)$ & $\mathbf{0 . 0 1 1}$ \\
\cline { 2 - 5 } & $\begin{array}{l}\text { Anxiety trait evaluated by } \\
\text { positive score at STAI B ** }\end{array}$ & $20.8 \%(13)$ & $10 \%(2)$ & 0.065 \\
\cline { 2 - 4 } & $\begin{array}{l}\text { General anxiety according a } \\
\text { Positive score at scale GAD } \\
7 * * *\end{array}$ & $44.2 \%(28)$ & $20 \%(5)$ & 0.139 \\
\hline $\begin{array}{l}\text { Psychotic } \\
\text { disorders }\end{array}$ & $\begin{array}{l}\text { Existence of at least one } \\
\text { current psychotic disorder in } \\
\text { the MINI }\end{array}$ & $9.5 \%(6)$ & $4.3 \%(1)$ & 0.437 \\
\hline
\end{tabular}

* MINI ( Mini International Neuropsychiatric Interview) ; **STAI (State trait anxiety scale) ; N : number of patient

\section{MOOD DISORDERS}

\section{MOOD DISORDERS EVALUATED BY NON SPECIFIC TOOLS}

The two groups did not differ in terms of presence of a current mood disorder at the MINI (respectively $15.9 \%$ vs $13 \%$; $=0.746$ ) and of depression according to positive score at scale Beck 21 ( respectively $18.8 \%$ vs $10 \% ; \mathrm{p}=0.623$ ).

\section{MOOD DISORDERS SCREENED BY SPECIFIC TOOL}

The temporal and the extra temporal groups did not differ in terms of depression according to positive score at NDDIE scale (respectively $27.5 \%$ vs $5.3 \% \mathrm{p}=0.113$ ).

\section{SPECIFIC MOOD DISORDERS}

For inter-ictal dysphoric disorder (respectively 25.4 vs $8.7 ; p=0.092$ ), there is no difference.

\section{DRUG-INDUCED MOOD DISORDERS}

The two groups did not differ in terme of the presence of a drug-induced mood disorder (respectively $14.3 \%$ vs $21.7 \% ; \mathrm{p}=0.407$ ).

\section{ANXIETY DISORDERS}

\section{ANXIETY DISORDERS EVALUATED BY NON SPECIFIC TOOLS}

A current anxiety disorder according to the MINI (respectively $36.5 \%$ vs $8.7 \%$; $=0.012$ ), a history of anxiety disorder in the MINI (respectively $30.2 \%$ vs $8.7 \%$; $=0.040$ ), as well as a 
positive result at STAI A ( respectively $11.3 \%$ vs $5 \% ; \mathrm{p}=0.011$ ) were more frequent in the temporal epilepsy group, as well as.

\section{ANXIETY DISORDERS SCREENED BY TOOL VALIDATED IN POPULATION WITH EPILEPSY}

The temporal and the extra temporal groups did no differ in terms of anxiety generalized according a positive score at scale GAD 7 (respectively $36.5 \%$ vs $17.4 \% ; \mathrm{p}=0.139$ )

\section{SPECIFIC ANXIETY DISORDER}

There was no diffrerence for anticipatory anxiety ( respectively $54 \%$ vs $47.8 \% ; p=0.614$ ) and avoidance resulting from anxiety ( temporal : 55,6 \% vs extra temporal 47,8\% p=0,525).

\section{DRUG-INDUCED ANXIETY DISORDERS}

The two groups did not differ concerning existence of a drug-induced anxiety disorder (respectively $3.2 \%$ vs $0 \% ; \mathrm{p}=0.387$ ).

\section{PSYCHOTIC DISORDERS}

\section{PSYCHOTIC DISORDERS EVALUATED BY NON SPECIFIC TOOL}

The temporal and the extra temporal groups did not differ in terms of existence of at least one current psychotic disorder at the MINI (respectively 9.5\% vs $4.3 \%$; $=0.437$ ), of existence of at least one antecedent psychotic at the MINI (respectively 7.9\% vs $0 \% ; p=0.164$ ) and of anti-psychotic treatment ( respectively $6.3 \%$ vs $0 \% ; \mathrm{p}=0.216$ ).

\section{SPECIFIC PSYCHOTIC DISORDERS}

The two groups did not differ in terms of existence of a feeling of patient persecution (respectively $9.5 \%$ vs $4.3 \% ; \mathrm{p}=0.203$ ), and the intensity of persecution ( respectively 7.1 ( $\mathrm{SD}: 1.5)$ vs $7(\mathrm{SD}: 0) ; \mathrm{p}=0.955)$.

\section{DRUG-INDUCED PSYCHOTIC DISORDERS}

The two groups did not differ regarding drug-induced psychotic disorders (respectively $4.8 \%$ vs $4.3 \%$; $\mathrm{p}=0.936)$.

\section{ADDICTIONS AND EATING DISORDER}

Temporal and extra temporal groups did not differ in terms of addictions and eating disorders. 


\section{4-EFFECT OF LIMBIC VS EXTRA LIMBIC EPILEPSY LOCALIZATION.}

42 out of 87 patients had a limbic epilepsy.

Patients in the limbic epilepsy group were significantly older than those in the extra-limbic epilepsy group (respectively 36.6 vs 31.5 year old in average; $\mathrm{p}=0.044$ ). Patients from the limbic epilepsy group had a significantly longer duration of epilepsy (respectively $21.1(14.4)$ vs 13.9 (10.9) ; p = 0.011), a more frequent history of febrile seizures (respectively $21.7 \%$ vs $5.1 \% ; \mathrm{p}=0.007)$, . Regarding the other characteristics of epilepsy, they did not differ from the extra-limbic epilepsy group.

Patients with limbic epilepsy took significantly less anti-epileptic treatments with known negative psychotropic effects (respectively 1.29 (SD: 0.72) vs 1.57 (SD: 0.95); p = 0.044).

\section{PSYCHIATRIC HISTORY}

Limbic and extra limbic epilepsy groups did not differ in terms of presence at least one psychiatric history at the MINI ( respectively $64.6 \%$ vs $56.4 \%$; p $=0.437$ ), at least one current psychiatric pathology at the MINI ( respectively $51.2 \%$ vs $53.8 \% ; \mathrm{p}=0.870$ ), psychiatric disorders before the onset of epilepsy ( respectively $29.2 \%$ vs $33.3 \%$; $=0.676$ ) and after the onset of epilepsy ( respectively $64.6 \%$ vs $51.3 \% ; \mathrm{p}=0.210$ ). 
Table 5: Comparison of inter-ictal psychiatric disorders according to limbic involvement of epilepsy.

\begin{tabular}{|c|c|c|c|c|}
\hline & & $\begin{array}{c}\text { LIMBIC } \\
\mathbf{N}=42 \\
\%(\mathrm{~N})\end{array}$ & $\begin{array}{c}\text { EXTRA } \\
\text { LIMBIC } \\
\text { N=45 } \\
\%(\mathrm{~N}) \\
\end{array}$ & $\mathbf{p}$ \\
\hline \multirow[t]{5}{*}{$\begin{array}{l}\text { Psychiatric } \\
\text { disorder }\end{array}$} & $\begin{array}{l}\text { History of psychological } \\
\text { follow-up }\end{array}$ & $52.1 \%(22)$ & $58.9 \%(27)$ & 0.520 \\
\hline & $\begin{array}{l}\text { Existence of at least one } \\
\text { psychiatric disorder before } \\
\text { onset of epilepsy }\end{array}$ & $29.2 \%(12)$ & $33.3 \%(15)$ & 0.676 \\
\hline & $\begin{array}{l}\text { Existence of at least one current } \\
\text { psychiatric disorder at the } \\
\text { MINI * }\end{array}$ & $52.1 \%(22)$ & $\begin{array}{l}53.8 \% \\
(24)\end{array}$ & 0.870 \\
\hline & $\begin{array}{l}\text { Existence of at least one } \\
\text { psychiatric history at the MINI } \\
*\end{array}$ & $64.6 \%(27)$ & $56.4 \%(25)$ & 0.437 \\
\hline & $\begin{array}{l}\text { Personal History of attempts of } \\
\text { suicide }\end{array}$ & $12.5 \%(5)$ & $15.4 \%(7)$ & 0.488 \\
\hline \multirow{3}{*}{$\begin{array}{l}\text { Mood } \\
\text { disorders }\end{array}$} & $\begin{array}{l}\text { Existence of at least one current } \\
\text { mood disorder at the MINI* }\end{array}$ & $16.7 \%(7)$ & $15.4 \%(7)$ & 0.871 \\
\hline & Interictal Dysphoric Disorder & $29.1 \%(12)$ & $12.8 \%(6)$ & 0.066 \\
\hline & $\begin{array}{l}\text { Antidepressant treatment in } \\
\text { progress }\end{array}$ & $16.7 \%(7)$ & $17.9 \%(8)$ & 0.875 \\
\hline \multirow{2}{*}{$\begin{array}{l}\text { Anxiety } \\
\text { disorders }\end{array}$} & $\begin{array}{l}\text { Existence of at least one current } \\
\text { anxiety disorder at the MINI* }\end{array}$ & $27.1 \%(11)$ & $30.8 \%(13)$ & 0.706 \\
\hline & $\begin{array}{l}\text { Anxiolytic treatment in } \\
\text { progress }\end{array}$ & $14.6 \%(6)$ & $5.1 \%(2)$ & 0.150 \\
\hline \multirow{2}{*}{$\begin{array}{l}\text { Psychotic } \\
\text { disorders }\end{array}$} & Isolated feeling of persecution & $12.5 \%(5)$ & $10.3 \%(5)$ & 0.744 \\
\hline & $\begin{array}{l}\text { Anti psychotic treatment in } \\
\text { progress }\end{array}$ & $8.3 \%(4)$ & 0 & 0.065 \\
\hline
\end{tabular}

* MINI ( Mini International Neuropsychiatric Interview) ; N : number of patient

\section{MOOD DISORDERS}

\section{MOOD DISORDERS EVALUATED BY NON SPECIFIC TOOLS}

Limbic and extra limbic groups did not differ in terms of mood disorders data evaluated in the MINI and depression according a positive score at scale Beck 21 (respectively $19.4 \%$ vs 15.8 $\% ; \mathrm{p}=0.680)$.

\section{MOOD DISORDERS SCREENED BY SPECIFIC TOOL}


No difference depression according a positive score at scale of NDDIE (respectively $29.4 \%$ vs $13.5 \% ; \mathrm{p}=0.101)$.

\section{SPECIFIC MOOD DISORDERS}

The two groups did not differ in terms of inter-ictal dysphoric disorder (respectively $29.1 \% \mathrm{vs}$ $12.8 \% ; \mathrm{p}=0.066)$.

\section{DRUG-INDUCED MOOD DISORDERS}

Limbic and extra limbic groups did not differ in terms of drug-induced mood disorders (respectively $18.5 \%$ vs $15.4 \% ; \mathrm{p}=0.679$ ).

\section{ANXIETY DISORDERS}

\section{ANXIETY DISORDERS EVALUATED BY NON SPECIFIC TOOLS}

Limbic and extra limbic did not differ in terms of existence of at least one current MINI anxiety disorder, at least one history of MINI anxiety disorder, anxiety state according positive score at scale STAI A (respectively $8.3 \%$ vs $13.2 \%$; $=0.504$ ) and anxiety trait according positive score at scale STAI B (respectively $22.2 \%$ vs $15.8 \% ; \mathrm{p}=0.480$ ).

\section{ANXIETY DISORDERS SCREENED BY TOOL VALIDATED IN POPULATION WITH EPILEPSY}

The two groups did not differ in terms of anxiety generalized according a positive score at scale GAD $7(45.7 \%$ vs $31.6 \% ; p=0.214)$

\section{SPECIFIC ANXIETY DISORDER}

The two groups did not differ in terms of anticipatory anxiety ( respectively $52.1 \%$ vs $53.8 \%$ ; $\mathrm{p}=0.870$ )neither for avoidance resulting from anxiety ( respectively vs 43,6 vs 35,$4 ; \mathrm{p}=0,564$ ).

\section{DRUG-INDUCED ANXIETY DISORDERS}

Limbic and extra limbic groups did not differ in terms of drug-induced anxiety disorders (respectively $2,1 \%$ vs $5,2 \% ; \mathrm{p}=0.439$ ).

\section{PSYCHOTIC DISORDERS}

\section{PSYCHOTIC DISORDERS EVALUATED BY NON SPECIFIC TOOL}

Limbic and extra limbic groups did not differ in terms of psychotic disorders. However, patients with limbic epilepsy tended to to take anti-psychotic treatment more frequently than patients with extra-limbic epilepsy (respectively $8 \%$ vs. $0 \%$; $\mathrm{p}=0.065$ ). 


\section{SPECIFIC PSYCHOTIC DISORDERS}

The two groups did not differ in terms of existence of a feeling of persecution of patients (respectively $12.5 \%$ vs $10.3 \% ; \mathrm{p}=0.744$ ), and the intensity of persecution (respectively 1.1 ( $\mathrm{SD}: 2.6)$ vs $0.8(\mathrm{SD}: 2.4) ; \mathrm{p}=0.490)$.

\section{DRUG-INDUCED PSYCHOTIC DISORDERS}

The two groups did not differ in terms of drug-induced psychosis (respectively $4.2 \%$ vs 5.1\%; $\mathrm{p}=0.831)$.

\section{ADDICTIONS AND EATING DISORDERS}

Limbic and extra limbic groups did not differ in terms addictive behaviors, eating disorders and drug-induced appetite disorders (respectively $20.9 \%$ vs $35.9 \% ; \mathrm{p}=0.118$ ).

\section{DISCUSSION}

Our study aimed to prospectively assess and describe the interictal psychiatric co-morbidities in an homogenous cohort of patients with refractory focal epilepsy in the clinical setting of an tertiary epilepsy monitoring unit. This was based on a systematic psychiatric assessment, hetero-evaluation and self-assessment tools. We also wanted to study the influence of the diagnostic criteria (non specific vs specific for epilepsy), the lateralization and localization of epilepsy on the prevalence of these co-morbiditites.

Anxiety disorders and mood disorders had been described as the two main psychiatric comorbidities in many studies (Scott et al., 2017). Our results on the overall population were similar to those of literature with $2 / 3$ of patients who had a psychiatric history according to the MINI (Mini International Neuropsychiatric Interview) and more than half with an ongoing psychiatric disorder at the MINI. (Jones et al., 2005)(Kanner, 2017, 2016)(Desai et al., 2010).

The prevalence of possible depression associated with chronic epilepsy based on a specific screening tool such as the NDDIE scale (17.2\%) was consistent with the prevalence reported in the literature (Jones et al., 2005).. This specific screening scale (NDDIE) was more sensitive than the non specific scale (for example the Beck 21 scale: 14.9\%) in our cohort. These findings were consistent with the literature regarding patients with all type of epilepsy 
(Gandy et al., 2012) (Gill et al., 2017) (de Oliveira et al., 2014). It is important to note that this prevalence in the present study was calculated on a specific population of patients with drug resistant focal epilepsy. The NDDIE scale has been scarcely used so far in this population, despite its simplicity and rapidity of use. This finding supports the recommendation to use NDDIE for better detection of depression in these patients with refractory focal epilepsy.

Our clinical approach focused on specific psychiatric comorbidities associated with epilepsy such as interictal dysphoric disorder (IDD) that was found in $21.8 \%$ of our cohort.

This prevalence was higher than the rate of mood disorder diagnosed according to the MINI (16.1\%) but consistent with previous studies (Amiri and Hansen, 2015; Mula et al., 2008). This was mainly related to the duration criteria for interictal dysphoric disorder which is shorter than in the MINI (less than 15 days). This may lead to under-diagnosis and undertreatment. Considering the strong correlation between mood disorders and quality of life in active epilepsies (Gilliam, 2002), it is essential to actively look for this disorder with specific clinical tools in patients with refractory focal epilepsy so that they can benefit from appropriate treatment and an improved quality of life.

Similarly, the use of a specific screening scale for anxiety disorders in patients with epilepsy (GAD 7), yielded a higher prevalence of anxiety (38.4\%) than the scales with non-specific criteria (28.7\% of patients at the MINI, $10.8 \%$ at the STAI A, and $18.9 \%$ at the STAI B).

Unlike previous studies (Jones et al., 2005) (Scott et al., 2017), anxiety disorders at inclusion were more frequent than mood disorders. This may be related to different factors: (i) the variability of the clinical tools used to assess anxiety. A recent metanalysis indeed underlined the variability of the anxiety disorder according to the diagnostic tools, by using a structured clinical interview (Scott et al., 2017); (ii) a greater sensitivity of neurologists to the mood than anxiety disorders. In fact, neurology teams are more sensitive to the mood disorder than anxiety disorders, which could lead to a general underestimation of anxiety disorders in the studies; (iii) the specific population of refractory focal patients with epilepsy; (iv) the specific context of psychiatric assessment during pre-surgical evaluation, for some patients eligible for surgery, that may in itself be a cause of increased anxiety.

It is essential, however, not to underestimate anxiety, a pathology that can potentially be complicated by suicide, and that re-emerges as a psychiatric emergency.

This highlights he need to generalize the use of the GAD7 questionnaire among neurologists taking care of patients with epilepsy. The GAD 7 self-questionnaire is indeed a specific fast 
and reliable screening tool that has been validated for anxiety disorders in epilepsy in different languages (Spitzer et al., 2006)(Seo et al., 2014)(Löwe et al., 2008)

Epilepsy is associated with an increased onset of psychiatric disorders and suicide before and after epilepsy diagnosis. These relations suggest common underlying pathophysiological mechanisms that both lower seizure threshold and increase risk of psychiatric disorders and suicide (Hesdorffer DC et al, 2012). Thus considering this bi-directionnal link between psychiatric disorders and epilepsy, the question has been long addressed of a common cerebral pathophysiological substrate and of anatomo-clinical correlations in epilepsy associated psychiatric co-morbidities.

We therefore looked for interactions between lateralization, localization of epilepsy on one hand and prevalence of specific psychiatric co-morbidities on the other hand.

We found a more frequent psychiatric history preceding epilepsy onset in patients with right lateralized epilepsy. This is an interesting finding which is consistent with the bidirectional relation between epilepsy and psychiatric comorbidity, perhaps with some difference according to the localisation. This point needs however to be replicated. We did not find a higher prevalence of psychiatric co-morbidities in right lateralized epilepsy in contrast with the findings of previous studies. In our study we even found a tendency for more frequent major depressive disorders and a significantly higher intensity of persecution experience in patients with left lateralized epilepsy. The higher prevalence of language and memory deficits in refractory left lateralized epilepsy, may explain this unexpected findings through the bidirectionnal link between cognitive impairment, stigma and psychiatric disorder. Indeed, in addition to having chronic and disabling seizures, patients with left lateralized epilepsy may have more difficulties in understanding and adjusting the surrounding world because of more frequent cognitive disturbance. It would be relevant for future studies to focus on this potential link between left epilepsy and psychiatric disorders.

Previous studies emphasized the higher prevalence of psychiatric disorders in temporal lobe epilepsy (Boulogne et al., 2015; de Oliveira et al., 2011, 2010). Other authors however challenged this findings and stressed the multifactorial hypothesis for the occurrence of psychiatric symptoms (Swinkels et al., 2006). Our findings may reconcile these contradictory studies. We found indeed a higher prevalence of non-specific psychiatric co-morbidities, 
especially anxiety disorders, but not of specific psychiatric co-morbidities in temporal lobe epilepsy.

We did not find a higher prevalence of psychiatric comorbidities in limbic epilepsy, regardless of the specificity of the diagnostic tools. This was rather unexpected because the limbic system is known to play a very important role in the regulation of emotions such as fear and pleasure and in the control of emotionally driven behaviors. There was however a strong trend towards higher prevalence of antipsychotic drug intake in patients with limbic epilepsy in our series suggesting a higher prevalence of associated psychosis in this subgroup. The $8 \%$ prevalence of chronic antipsychotic treatment in limbic epilepsy is extremely high considering the $2 \%$ prevalence of psychosis in the general population. Another explanation could be that this classification was based on the identification of the epileptogenic zone, in other words, the area of seizure initiation. During the inter-ictal phase, the area of functional disturbance as assessed for example by interictal FDG-PET is usually larger than the epileptogenic zone and involves both the epileptogenic and the propagation zone (Chassoux et al., 2004). In cases of lateral temporal epilepsy (extra-limbic according to our definition), it is very likely that the medial temporal structures were functionally disturbed because they are almost systematically involved in the propagation zone. Those cases were therefore classified as extra-limbic whereas an interictal disturbance of limbic structures was very likely. This may explain why temporal lobe and not limbic epilepsy according to our definition were associated with higher prevalence of psychiatric co-morbidities.

These heterogeneous results strongly support that the expression of psychiatric symptoms in patients with epilepsy is the result of a complex interaction between socio-demographic, clinical, iatrogenic and neurobiological factors.

Finally, the absence of correlations between addictive disorders and characteristics of epilepsy may be related to the lack of power of our cohort considering the low prevalence of these disorders in our cohort.

CONCLUSION 
Despite the above discussed inherent selection bias related to the recruitment in a tertiary epilepsy center, the high frequency of psychiatric disorders in this cohort and the specificity of the symptomatology underline the importance of an extended, specialized and specific psychiatric evaluation for these patients with active refractory focal epilepsy.

The second important finding of our study was the high rate of anxiety disorders in drugresistant, focal patients with epilepsy that were probably more often underdiagnosed than mood disorders. It is important to remember that there is an important link between anxiety disorders and control of epileptic seizures. This link is bidirectional as a patent anxiety disorder has a pejorative effect on the frequency of seizures, and the repetition of seizures maintains anxiety.

It is necessary to use a specific screening methodology to be able to highlight these anxiety disorders, treat them, and improve the quality of life of patients.

Thanks to Dr. Lucie Hopes for her corrections in English 
Amiri, M., Hansen, C.P., 2015. The interictal dysphoric disorder in patients with epilepsy: A doubtful disorder lacking diagnostic tools. Seizure 24, 70-76.

https://doi.org/10.1016/j.seizure.2014.08.009

Boulogne, S., Catenoix, H., Ryvlin, P., Rheims, S., 2015. Long-lasting seizure-related anxiety in patients with temporal lobe epilepsy and comorbid psychiatric disorders. Epileptic Disord 17, 340-344. https://doi.org/10.1684/epd.2015.0757

Chassoux, F., Semah, F., Bouilleret, V., Landre, E., Devaux, B., Turak, B., ... \& Roux, F. X. (2004). Metabolic changes and electro-clinical patterns in mesio-temporal lobe epilepsy: a correlative study. Brain, 127(1), 164-174.

de Oliveira, G.N., Lessa, J.M.K., Gonçalves, A.P., Portela, E.J., Sander, J.W., Teixeira, A.L., 2014. Screening for depression in people with epilepsy: comparative study among neurological disorders depression inventory for epilepsy (NDDI-E), hospital anxiety and depression scale depression subscale (HADS-D), and Beck depression inventory (BDI). Epilepsy Behav 34, 50-54. https://doi.org/10.1016/j.yebeh.2014.03.003

de Oliveira, G.N.M., Kummer, A., Salgado, J.V., Filho, G.M. de A., David, A.S., Teixeira, A.L., 2011. Suicidality in temporal lobe epilepsy: measuring the weight of impulsivity and depression. Epilepsy Behav 22, 745-749. https://doi.org/10.1016/j.yebeh.2011.09.004

de Oliveira, G.N.M., Kummer, A., Salgado, J.V., Portela, E.J., Sousa-Pereira, S.R., David, A.S., Teixeira, A.L., 2010. Psychiatric disorders in temporal lobe epilepsy: an overview from a tertiary service in Brazil. Seizure 19, 479-484. https://doi.org/10.1016/j.seizure.2010.07.004

Desai, S.D., Shukla, G., Goyal, V., Singh, S., Padma, M.V., Tripathi, M., Srivastava, A., Singh, M., Shivakumar, K., Sagar, R., Behari, M., 2010. Study of DSM-IV Axis I psychiatric disorders in patients with refractory complex partial seizures using a short structured clinical interview. Epilepsy Behav 19, 301-305. https://doi.org/10.1016/j.yebeh.2010.07.005

Gandy, M., Sharpe, L., Perry, K.N., Miller, L., Thayer, Z., Boserio, J., Mohamed, A., 2012. Assessing the efficacy of 2 screening measures for depression in people with epilepsy. Neurology 79, 371-375. https://doi.org/10.1212/WNL.0b013e318260cbfc

Gill, S.J., Lukmanji, S., Fiest, K.M., Patten, S.B., Wiebe, S., Jetté, N., 2017. Depression screening tools in persons with epilepsy: A systematic review of validated tools. Epilepsia 58, 695-705. https://doi.org/10.1111/epi.13651

Hesdorffer DC1, Ishihara L, Mynepalli L, Webb DJ, Weil J, Hauser WA.Epilepsy, suicidality, and psychiatric disorders: a bidirectional association. Ann Neurol. 2012 Aug;72(2):184-91. doi: 10.1002/ana.23601. Epub 2012 Aug 7.

Jones, J.E., Hermann, B.P., Barry, J.J., Gilliam, F., Kanner, A.M., Meador, K.J., 2005. Clinical assessment of Axis I psychiatric morbidity in chronic epilepsy: a multicenter investigation. J Neuropsychiatry Clin Neurosci 17, 172-179. 
https://doi.org/10.1176/jnp.17.2.172

Kanner, A.M., 2017. Psychiatric comorbidities in new onset epilepsy: Should they be always investigated? Seizure 49, 79-82. https://doi.org/10.1016/j.seizure.2017.04.007

Kanner, A.M., 2016. Psychiatric comorbidities in epilepsy: Should they be considered in the classification of epileptic disorders? Epilepsy Behav 64, 306-308.

https://doi.org/10.1016/j.yebeh.2016.06.040

Krishnamoorthy, E.S., Trimble, M.R., Blumer, D., 2007. The classification of neuropsychiatric disorders in epilepsy: a proposal by the ILAE Commission on Psychobiology of Epilepsy. Epilepsy Behav 10, 349-353.

https://doi.org/10.1016/j.yebeh.2006.10.002

Kwan, P., Arzimanoglou, A., Berg, A.T., Brodie, M.J., Allen Hauser, W., Mathern, G., Moshé, S.L., Perucca, E., Wiebe, S., French, J., 2010. Definition of drug resistant epilepsy: consensus proposal by the ad hoc Task Force of the ILAE Commission on Therapeutic Strategies. Epilepsia 51, 1069-1077. https://doi.org/10.1111/j.1528-1167.2009.02397.x

Kwon, O.-Y., Park, S.-P., 2014. Depression and Anxiety in People with Epilepsy. Journal of Clinical Neurology 10, 175-188. https://doi.org/10.3988/jcn.2014.10.3.175

Löwe, B., Decker, O., Müller, S., Brähler, E., Schellberg, D., Herzog, W., Herzberg, P.Y., 2008. Validation and standardization of the Generalized Anxiety Disorder Screener (GAD-7) in the general population. Med Care 46, 266-274.

https://doi.org/10.1097/MLR.0b013e318160d093

Maillard L, Vignal JP, Gavaret M, Guye M, Biraben A, McGonigal A, Chauvel P, Bartolomei F.Semiologic and electrophysiologic correlations in temporal lobe seizure subtypes.

Epilepsia. 2004 Dec;45(12) DOI:10.1111/j.0013-9580.2004.09704.x

Micoulaud-Franchi, J.-A., Barkate, G., Trébuchon-Da Fonseca, A., Vaugier, L., Gavaret, M., Bartolomei, F., McGonigal, A., 2015. One step closer to a global tool for rapid screening of major depression in epilepsy: validation of the French NDDI-E. Epilepsy Behav 44, 11-16. https://doi.org/10.1016/j.yebeh.2014.12.011

Micoulaud-Franchi, J.-A., Bartolomei, F., Duncan, R., McGonigal, A., 2017. Evaluating quality of life in epilepsy: The role of screening for adverse drug effects, depression, and anxiety. Epilepsy Behav 75, 18-24. https://doi.org/10.1016/j.yebeh.2017.07.016

Micoulaud-Franchi, J.-A., Lagarde, S., Barkate, G., Dufournet, B., Besancon, C., TrébuchonDa Fonseca, A., Gavaret, M., Bartolomei, F., Bonini, F., McGonigal, A., 2016. Rapid detection of generalized anxiety disorder and major depression in epilepsy: Validation of the GAD-7 as a complementary tool to the NDDI-E in a French sample. Epilepsy Behav 57, $211-$ 216. https://doi.org/10.1016/j.yebeh.2016.02.015

Mula, M., Jauch, R., Cavanna, A., Collimedaglia, L., Barbagli, D., Gaus, V., Kretz, R., Viana, M., Tota, G., Israel, H., Reuter, U., Martus, P., Cantello, R., Monaco, F., Schmitz, B., 2008. Clinical and psychopathological definition of the interictal dysphoric disorder of epilepsy. Epilepsia 49, 650-656. https://doi.org/10.1111/j.1528-1167.2007.01434.x 
Regier, D.A., Kaelber, C.T., Roper, M.T., Rae, D.S., Sartorius, N., 1994. The ICD-10 clinical field trial for mental and behavioral disorders: results in Canada and the United States. Am J Psychiatry 151, 1340-1350. https://doi.org/10.1176/ajp.151.9.1340

Seo, J.-G., Cho, Y.W., Lee, S.-J., Lee, J.-J., Kim, J.-E., Moon, H.-J., Park, S.-P., 2014. Validation of the generalized anxiety disorder-7 in people with epilepsy: a MEPSY study. Epilepsy Behav 35, 59-63. https://doi.org/10.1016/j.yebeh.2014.04.005

Sheehan, D.V., Lecrubier, Y., Sheehan, K.H., Amorim, P., Janavs, J., Weiller, E., Hergueta, T., Baker, R., Dunbar, G.C., 1998. The Mini-International Neuropsychiatric Interview (M.I.N.I.): the development and validation of a structured diagnostic psychiatric interview for DSM-IV and ICD-10. J Clin Psychiatry 59 Suppl 20, 22-33;quiz 34-57.

Spitzer, R.L., Kroenke, K., Williams, J.B.W., Löwe, B., 2006. A brief measure for assessing generalized anxiety disorder: the GAD-7. Arch. Intern. Med. 166, 1092-1097. https://doi.org/10.1001/archinte.166.10.1092

Spitzer, R.L., Kroenke, K., Williams, J.B.W., Löwe, B., 2006. A brief measure for assessing generalized anxiety disorder: the GAD-7. Arch. Intern. Med. 166, 1092-1097. https://doi.org/10.1001/archinte.166.10.1092

Swinkels, W.A.M., van Emde Boas, W., Kuyk, J., van Dyck, R., Spinhoven, P., 2006. Interictal depression, anxiety, personality traits, and psychological dissociation in patients with temporal lobe epilepsy (TLE) and extra-TLE. Epilepsia 47, 2092-2103. https://doi.org/10.1111/j.1528-1167.2006.00808.x

Tedrus, G.M. de A.S., Fonseca, L.C., Carvalho, R.M., 2013. Epilepsy and quality of life: socio-demographic and clinical aspects, and psychiatric co-morbidity. Arq Neuropsiquiatr 71, 385-391. https://doi.org/10.1590/0004-282X20130044

Toffol, B. de, 2003. Les troubles psychiatriques dans l'épilepsie. Epilepsies 15, 63-70.

Vaaler, A.E., Morken, G., Iversen, V.C., Kondziella, D., Linaker, O.M., 2010. Acute Unstable Depressive Syndrome (AUDS) is associated more frequently with epilepsy than major depression. BMC Neurol 10, 67. https://doi.org/10.1186/1471-2377-10-67 